\title{
Una mirada a los estudios hegelianos en México. Entrevista con José Ignacio Palencia
}

\author{
Efraín Lazos
}

$\mathrm{E}$

fraín Lazos: Comencemos con una consideración muy general. Ante el "regreso a Hegel" es preciso notar que si hay alguien entre nosotros que a lo largo de las últimas cuatro décadas ha mostrado consistencia en su dedicación a los estudios de la filosofía de Hegel, ése es José Ignacio Palencia. ¿Cómo aprecias hoy, desde el punto de vista privilegiado que te da esa consistencia, los estudios hegelianos en México? ¿Cómo describirías su situación actual?

José Ignacio Palencia: Siento o percibo que hay mayor interés que hace cuarenta años cuando me inicié como profesor en la UNAM..., más en Hegel mismo que por ejemplo en el criticado por Marx o por el marxismo soviético. Se está descubriendo en Hegel un nuevo sentido, lo que ha llevado, además, a revalorar a Schelling y a Kant -y aún a Fichte, en cierta medida-, sin ignorar las diferencias entre ellos.

Hubo una etapa anterior en que grosso modo la filosofía se explicaba tomando en cuenta a Hegel, así fuera para polemizar contra él -o pretendiendo ignorarlo- volviéndose a Kant, por ejemplo. Luego vinieron las interpretaciones, apropiaciones y desarrollos, o la discusión sobre desarrollos, así fueran polémicos, que en su origen lo tuvieron presente, o que han querido deshacerse de él, en no pocas ocasiones, a mi ver, sin lograrlo [como el positivismo].

Kant es ineludible; Hegel puede ser un lujo: la posibilidad de pensar dialécticamente, comprender, superar - no anular- las tensiones entre elementos o polos opuestos - unidad/diversidad, identidad/diferencia, con sus consecuencias posibles [como condiciones] para la tolerancia social cultural y política.

E. Lazos: Cuéntanos un poco de tus comienzos. ¿Cómo describirías el ambiente intelectual en el que te hiciste filósofo-qué ideas sobre la filosofía predominaban, qué autores y corrientes eran las más influyentes? ¿Cuándo 
fue que te interesaste por primera vez en Hegel? ¿Qué aspectos de su obra despertaron tu curiosidad, tu motivación? ¿Cuál era el "acceso” a Hegel, a sus obras, a sus comentaristas?

J. I. Palencia: Yo llegué a la Facultad desde las humanidades clásicas. Tengo una licenciatura por ahí -Platón, los trágicos griegos, Cicerón, Horacio, Virgilio, Julio César, los historiadores griegos y latinos, y otros... Homero, sólo en español, pero sí. Y mis antecedentes filosóficos eran más bien de escolástica, suareziana aunque abierta, ni siquiera tomista, lo que acaso sería una ventaja. Textos de Tomás y Aristóteles, no conocía antes de llegar a la Facultad de Filosofía y Letras.

En ese tiempo todos los alumnos debíamos iniciar con Nicol, presocráticos y muy poco Platón. [Nicol] era aterrador para muchos, repetían y repetían los cursos con él sin atreverse a presentar el examen ni seguir adelante. Yo inicié un semestre antes con Miguel León-Portilla: la Filosofía náhuatl, y completaba con Paco de la Maza y Justino Fernández - mi inclinación intuitiva era la antropología, pero en la ENAH de entonces, muy cargada a la arqueología, y refundida por el rumbo del Zócalo, no encontré la riqueza de la Facultad en CU.

En la Facultad había todavía más de un profesor neokantiano como Adalberto García de Mendoza, y algunos escolásticos como Oswaldo Robles y José Luis Curiel, pero había la libertad de elegir profesores y cursos conforme al interés del alumno.

Sobre las corrientes, reflexionándolo ahora, había todavía, más que ahora, una presencia o herencia francesa: Sartre, Bergson, Mournier, Marcel, y quizá Merlau-Ponty; Maritain y Gilson para los neoescolásticos; de los existencialistas, Jaspers; otros como Scheller. De los profesores más jóvenes, todos eran alumnos de José Gaos: Vera Yamuni trabajaba la lógica de Quine; Luis Villoro había publicado sobre Husserl; Ricardo Guerra ya trabajaba textos de Heidegger; Fernando Salmerón vino de Alemania con el positivismo lógico. Otros cultivaban o hablaban de un humanismo que para mí siempre fue muy abstracto, quizá referido a la Paideia de Jaeger. El canónigo Gallegos Rocafull y fray Alberto de Ezcurdia conocían a santo Tomás, pero eran ambos muy críticos del tomismo cerrado y de la escolástica muerta. El primero a quien oí hablar de Hegel fue [Adolfo] Sánchez Vázquez en un semestre de Historia VII en el que no habló de Marx sino como crítico de Hegel; el semestre siguiente, segundo del curso 1963, sí impartió [Sánchez Vázquez] la Filosofía de Marx, en un curso sobre los Manuscritos recién traducidos.

Sobre Hegel, ya en la maestría, tuvimos varios seminarios con Guerra, antecedentes, coincidentes y consecuentes a la publicación por el Fondo [de Cultura Económica] de la Fenomenología del espíritu. Yo todavía alcancé un seminario con Gaos -el último que impartió en la Facultad y [que] terminó, por su renuncia a la UNAM, en el Colegio de México. En él, per summa capi- 
ta, revisamos la Ciencia de la lógica durante un semestre; de ahí en adelante trabajé por mí mismo.

Estos inicios no son muy precisos, pero indudablemente se vinculan con el trabajo sobre la Fenomenología en los seminarios con Guerra; quizá entonces no así formulado, pero Hegel llamaba a "pensar el presente" y a pensarlo dialécticamente. En los seminarios con Guerra se discutía esto muy ampliamente; era una generación muy brillante: Juan Garzón, Carlos Pereyra, Santiago Ramírez Castañeda -tempranamente fallecidos los tres-, Bolívar Echeverría, el más consistente de todos en su posición; de los jóvenes, Luis Salazar, Mercedes Garzón, Mariflor Aguilar, que recuerde; también profesores: José Cueli y Santiago Ramírez, padre -psicoanalistas los dos-, Carlos Félix y otros más. En el fondo, con Hegel se relativizaba cualquier dogmatismo, cualquier pensamiento totalizante y lineal, de verdad absoluta. Lo mismo nos podíamos abrir a Marcuse, estábamos en 1968-1969, que discutir el marxismo mecanicista y cerrado, staliniano y dogmático, sin dejar de estimar las aportaciones de Marx -Sánchez Vázquez publicó su Filosofía de la praxis en 1967. En 1968 todo esto era importante: pensar la alteridad, afirmar la libertad, buscar la racionalidad; Hegel y sus expositores o comentadores - he citado ya a Marcuse, pero además Hyppolite, Kojeve, Luckacs...- y todo surgía o cabía en su discusión: el absoluto-relativo; el espíritu inmanente al mundo y a la historia; la crítica a las almas bellas y a los imperativos categóricos; la actividad transformadora de la realidad.

Como profesor recuerdo haber abordado textos de Hegel en el curso optativo de Filosofía de la religión aunque no podría ahora afirmar si esto fue desde el primero que di en 1969. Siempre me ha parecido importante el sentido que tiene para él la religión como representación (Vorstellung) del desarrollo del espíritu, en esa inmediatez que es ahí pero no se encuentra -o reconoce- en el saber. Hegel aborda el tópico del culto desde el capítulo primero en la Fenomenología, el de la afirmación del más allá en el capítulo de la autoconciencia (cap. IV) cuando habla del desgarramiento entre el más acá y el más allá, de la fe como pensamiento enfrentado al de la Ilustración, en el capítulo sexto, y al desarrollo de la religión destina completo el capítulo séptimo; todavía las primeras páginas sobre el saber (cap. VIII) retoman este tópico. Para él, aparte de textos anteriores que entonces yo no conocía, y de los varios cursos de lecciones [sobre filosofía de la religión] al final de su vida, el tema es importante. Yo había llevado un curso sobre filosofía de la religión con Villoro: Otto, Van der Loewe, Frazer, Eliade, pero el enfoque de Hegel, sin contraponerse a aquél, lo enriquecía, le daba organicidad. Particularmente recuerdo haber trabajado en un curso mío, las cuatro páginas sobre la obra de arte viviente con referencia a las Bacantes de Eurípides y a la expresión espiritual en la corporeidad dentro de la danza contemporánea. 
El problema para el curso [de filosofía de la religión] venía de los alumnos: había quienes buscaban expresiones o experiencias místicas, o bien una crítica ni siquiera como la de Feuerbach sino la que caracteriza Marx en la Tesis I sobre Feuerbach como el materialismo vulgar anterior a Kant. Tampoco me interesaba a mí la apologética decimonónica, que entre nosotros se mantuvo hasta bien entrado el siglo Xx. Por eso, con el tiempo, dejé el curso. Sí presenté sobre este tema una ponencia en el primer coloquio de filosofía que fue en Morelia (1975), antecedente de los congresos de la Asociación [Filosófica de México]. La revisé para este caso y la considero aún aceptable para mí. En 1978 se publicaron en español los Escritos de juventud de Hegel; Gabriel Vargas me pidió una recensión para Dialéctica. El tema de la religión es en ellos recurrente, sobre todo como "positividad" en el judaísmo y el cristianismo, pero hay otros temas importantes: el de la vida y el amor, la crítica al Estado, el programa del sistema, etcétera.

Cuando Ricardo Guerra dejó la dirección de la Facultad y fue a Alemania como embajador, un grupo de compañeros me pidió que sostuviera o mantuviera su seminario sobre Ontología en el posgrado. (Ya tenía yo la maestría y había impartido algunos cursos monográficos en el posgrado. Por otra parte ya estaba vigente la tajante división entre cursos y seminarios de licenciatura y de posgrado.) Abordamos la Ciencia de la lógica pero no avanzamos mucho en ella; preferí volver a la Fenomenología y aun después del regreso de Guerra a México y a nuestra Facultad, trabajé en este seminario hasta la huelga del 2000, incluida -no únicamente la Fenomenología-, la Filosofía del derecho y otros más.

Tuve ocasión de trabajar la Ciencia de la lógica completa durante dos periodos discontinuos en seminarios de licenciatura (cinco o seis semestres en cada uno). Existía además un curso monográfico en el plan antiguo de licenciatura, la Filosofía de Hegel. En él tuvo cabida la revisión de muchos textos con alumnos; en algunas ocasiones alternando y prosiguiendo temas de los seminarios de licenciatura o del posgrado. Después de la huelga [del 2000] y con la modificación del plan de estudios me centré en dos rubros: Problemas de metafísica y ontología, y Seminario optativo; en este último mi opción era Hegel; la de los alumnos podía ser la de los textos o temas del autor. En el primero, cupo relativizar a Hegel o, con Hegel, otros temas, por ejemplo, la crítica a la metafísica moral de Kant. Alguna vez volví al tema de la religión con Hegel, desde la ontología.

El curso más reiterado, sin embargo, fue el de Ontología: en la primera mitad de la década de los ochentas estaba yo con Carlos Pereyra en la coordinación [del Colegio de Filosofía] y se retiraron a la vez dos profesores que tenían el curso. El propio Pereyra lo había impartido varias veces cuando lo dejó Ricardo Guerra, y seguía ante todo a Kant. Mi propuesta fue sencilla: 
proceder de acuerdo en la mañana y en la tarde, conservando cada profesor su enfoque pero con unidad fundamental en la temática. Entramos Rodolfo Cortés del Moral -quien había sido alumno mío y de Guerra-, y yo, en la tarde; así se ha mantenido con sustituciones por parte de quienes han sido mis alumnos e incluso, algunos ayudantes en el curso: Elisabetta Di Castro, Omar Jiménez, Ricardo Vázquez... Creo que, como opción, ha sido relevante: la asignatura es básica y obligatoria aunque se puede sustituir por Metafísica, o seguir otros enfoques en su tratamiento. Para mí, antes de entrar en críticos como Heidegger, por ejemplo, es importante conocer aquello que se quiere criticar. Para nuestro momento, Kant sigue siendo un autor fundamental, Hegel un referente relevante. Si se quiere, por ejemplo, abordar actualmente el tema o el problema del sujeto, es importante pero, ¿dónde surge el tema y cómo se propone si no es en referencia a Kant, Hegel, o a los dos?, así sea criticando sus exposiciones. Así concebí el curso: un semestre para el pensamiento crítico, otro al pensamiento dialéctico, con un subproducto compartido: no tanto hablar de los autores sino conocerlos y trabajarlos en sus textos. Esta enseñanza se la debo a Gaos y él en segundo año de licenciatura nos llevaba a trabajar sobre los textos - no se trata de convencer a los alumnos de convertirse en hegelianos o kantianos, sino de capacitarlos para que puedan trabajar a Kant y a Hegel. Por supuesto hay otros referentes importantes. De los antecedentes, Aristóteles, Descartes, Hume; consecuentes, Marx, Nietzsche, Heidegger, importantes sin duda, pero referentes; en otros cursos o aún conmigo en optativas podrá volverse a ellos.

E. Lazos: Es un dato curioso y tal vez revelador: En 1944, el Fondo de Cultura Económica publica Hegel y el idealismo, de W. Dilthey, traducido por Eugenio Ímaz. Dedicado a los escritos juveniles del filósofo suabo, e independientemente de las motivaciones de los editores, tiene la importancia de ser, hasta donde sé, el primer libro sobre Hegel aparecido en México; catorce años después, el Fondo publica la traducción de Roces y Guerra de la Fenomenología, la primera en español; y ya en el setenta y ocho se publica la traducción de José María Ripalda de los Escritos de juventud, que contiene el material para apreciar de primera mano el ensayo de Dilthey. ¿Qué reflexiones te merece esto?

Por otro lado, con el bicentenario de su primera edición, apareció una nueva traducción al español de la Fenomenología. En los ochentas se había publicado en Argentina una versión distinta a la de Roces-Guerra. No es difícil prever que aparecerán otras versiones. ¿Qué recomendarías para futuras ediciones? ¿Qué otras obras de Hegel, y qué obras sobre Hegel serían, en tu opinión, deseable editar?

J. I. Palencia: La traducción de la Fenomenología publicada por el Fondo, y en mucho tiempo la única en español, fue importante: "un Hegel mucho más 
vital que el del Sistema”, comentaba alguna vez Bolívar Echeverría. Del sistema, además de la Ciencia de la lógica de los Mondolfo (1956) no teníamos mucho a mano en español: la Lógica de la Enciclopedia [de las ciencias filosóficas], traducida por Zozaya en el siglo XIX aunque reeditada todavía en el nuestro [el siglo XXI]; la mala traducción de Ovejero de la Enciclopedia (1940) que se sigue reimprimiendo en Argentina y México; una traducción de Gaos de las Lecciones de filosofía de la historia en la Revista de Occidente de Madrid (1926), casi inencontrable entre nosotros hasta que fue reimpresa por Alianza; las Lecciones de historia de la filosofía en traducción de Roces aparecieron en 1955; en 1975 apareció la traducción de Vermal de la Filosofía del derecho, corregida en 1988; aunque hay otras, de las que no tengo fecha exacta de primeras ediciones. Ahora tenemos la edición crítica de Ilting publicada en español por Carlos Díaz (1993); de 1998 es la edición de las Lecciones sobre filosofía de la religión; de la Estética hay una versión publicada en 1980 sobre el texto completo establecido por Hotho, y una reciente (2006) sobre los apuntes de Kehler. Es también relativamente reciente la versión de la Enciclopedia por Valls Plana (1997) y he oído que también se prepara en España una nueva versión de la Ciencia de la lógica. De las obras menores, los artículos de Jena, los cursos de la propedéutica, y la Filosofía real, hay también ahora ediciones en español. No todas tan cuidadas y legibles como las traducciones de José María Ripalda que publica el Fondo [de Cultura Económica]. Textos, pues, hay suficientes para trabajar; por supuesto que el original alemán sigue siendo indispensable cuando se quiere llegar a ciertos niveles.

De las ediciones de la Fenomenología: la argentina sólo la conocí por encima. Sobre la edición española reciente coincido con la opinión que publicaste tú en Diánoia. Con alumnos veo preferible todavía trabajar con la publicada en el Fondo, a la que se le podrían añadir algunas notas puntuales, pero con respeto a la traducción Roces-Guerra. De hecho, con [Gonzalo] Celorio en [la dirección de] el Fondo [de Cultura Económica], Guerra pretendía trabajar algo así; pero Celorio duró en el Fondo no más de un año y Guerra ya falleció. No sé quién pudiese, con acierto, acometer tal empresa sin causar destrozos al texto.

De los comentarios a la obra de Hegel, ya mencionaba yo algunos al hablar de los seminarios con Guerra; el de Dilthey, por el historicismo de éste, no gozaba de mayor estima entre nosotros. El Instituto de Investigaciones Filosóficas tuvo la oportunidad de traducir, de Charles Taylor, el Hegel; por la demora en hacerlo, perdió la licencia. Actualmente hay mucho ya escrito y publicado en alemán, en ingles, en francés, y en español, [esto] puede ser un alud. Hay comentarios de autores muy relevantes, pero que como comentarios son objetables, pienso en Gadamer o en Heidegger. 
E. Lazos: El "regreso a Hegel" es innegable. La expresión es por supuesto sintomática y, en todo caso, sólo parcialmente correcta. No obstante, permite referirnos al proceso inverso: el abandono o, en algunos casos, la huida y el rechazo de Hegel. El fenómeno fue, de algún modo, internacional, pero en México, como es natural, adquirió sus propios matices. Es llamativo que en lo que podría considerarse la primera generación de filósofos "profesionales" -me refiero a la generación que recibió su primera formación con los transterrados, sobre todo Gaos, Nicol-, se produjo, hacia la mitad de los sesentas, una ruptura bastante consciente con el pensamiento alemán y con el hegelianismo en particular. En un caso emblemático, quien se había titulado con una tesis sobre la Ciencia de la lógica, pasó en pocos años a escribir sobre la teoría de las descripciones de Russell y sobre la filosofía del lenguaje de Wittgenstein. ¿A qué atribuyes esa ruptura? ¿Cuáles fueron, dirías, sus efectos sobre los estudios hegelianos en México? ¿Qué nos puedes decir sobre esa época?

J. I. Palencia: No es para mí tan patente este abandono y regreso, mas pudiera decirse que se trata de un lento devenir - en palabras de Hegel- de imágenes que desfilan con suma lentitud. Quien tú mencionas, no sólo se alejó de Hegel sino de la filosofía y de la academia. El propio Gaos solía referirse a quienes fueron sus alumnos en México, caracterizándolos por generaciones: los historiadores, Justino Fernández, Edmundo O'Gorman, quizá Leopoldo Zea, entre ellos; los heideggerianos o hiperiones, Guerra, Villoro, Emilio Uranga, Jorge Portilla, Joaquín Sánchez McGrégor, y otros; entre los hegelianos, ubicaba a Sánchez Vázquez y a Alejandro Rossi -todo esto referido a los textos y temas que habían trabajado con él.

Los hiperiones se presentaron en público hablando del existencialismo francés; Guerra en concreto sobre la libertad en la obra de Sartre. (Habría que ponderar el peso de Hegel en El ser y la nada.) No hay que olvidar que Guerra fue a Francia para obtener su doctorado con Jean Hyppolite, traductor y comentarista de la Fenomenología del espíritu; tampoco que Sánchez Vázquez venía de la Guerra [civil] en España, y era parte del Partido Comunista Español en el exilio. Indudablemente en cada uno de ellos, y por su parte en Villoro, hay trayectorias diversas. Guerra fue a Alemania en busca de Heidegger, Sánchez Vázquez nunca accedió a la fascinación que representara Althusser para sus alumnos más jóvenes, y polemizó directamente con él. A Villoro, sobre todo en los últimos años, le siguen preocupando temas tales como el derecho de los pueblos a estar en la historia, la libertad realizada en concreto, la pluralidad de culturas. Estamos ante temas y posturas que, diría yo, están en Hegel; aunque Hegel no sea la Biblia o el libro canónico y único a interpretar unilateralmente sino quien inspira y ayuda a pensar el presente: no el presente de Hegel sino nuestro propio presente, para lo cual él nos ha legado el recurso de aprender a pensar dialécticamente. 
E. Lazos: Entre quienes podrían haber resultado aliados naturales de Hegel, los estudiosos y seguidores de Karl Marx, las cosas no pintaron mejor, según creo, para los estudios hegelianos. La obra de Louis Althusser, que fue ampliamente estudiada entre nosotros, fincaba su interpretación de Marx sobre la base de que habia que discernir los trabajos "metafísicos" de los propiamente "científicos" en la obra marxiana; con los primeros él asociaba, en su prejuicio, la sombra de Hegel. Curiosamente, entre los defensores de la unidad y consistencia del pensamiento marxiano, pienso sobre todo en Sánchez Vásquez, la presencia de Hegel siguió siendo, por ponerlo así, oblicua -recuperó la importancia de las ideas estéticas del suabo, que no su filosofía política y de la historia. ¿Coincides, en términos generales, con este diagnóstico preliminar? ¿Qué matices le harías? A tu juicio, ¿qué efectos ha tenido el marxismo sobre el estudio de Hegel?

J. I. Palencia: De mi propia experiencia te puedo repetir que Sánchez Vázquez nunca fue althusseriano, y añadiría que en su tesis doctoral rompía ya con el estalinismo dogmático; su tratamiento de Hegel en el texto de Filosofía de la praxis es compatible con las posiciones de Marx, explicable y comprensible por muchas razones, pero no compartido por mí en este punto, pues considero que hay muchos puntos en Hegel que Marx soslayó.

Sobre los conocedores de Marx, no quisiera yo entrar en discusión sobre sus interpretaciones de Hegel o Marx en este momento. Baste decir que muchos alumnos marxistas se han acercado a mis seminarios y cursos en licenciatura y en posgrado, acaso movidos por lo que Hegel sí puede enseñarnos, y lo que enseñó a Marx y Engels: asumir la negatividad, pensar dialécticamente, buscar ser sujeto y no objeto en el proceso de la historia.

E. Lazos: Háblanos un poco de la actualidad de Hegel. Los últimos cuarenta años han dejado ver una serie de cambios insospechados en el mundo humano y en la forma en que las personas se entienden a sí mismas y a su entorno. Vivimos, acaso, "en tiempos de gestación y de transición hacia una nueva época". Ahora bien, por un lado, parece haber una cierta urgencia por comprender el mundo humano, sus logros y fracasos, en tanto que totalidad; por otro, sin embargo, nos hemos acostumbrado, quizás justificadamente, a tener reservas frente a las concepciones omniabarcantes del mundo. ¿Qué aspecto del pensamiento de Hegel crees que debe estar presente, hoy, en el esfuerzo de autocomprensión y autotransformación de las sociedades y las personas?

Finalmente, una pregunta sobre la religión. Hace un par de años, Joseph Ratzinger, en su ya célebre discurso de Ratisbona, fustigó al islam evocando a un papa del siglo catorce, quien afirmaba, palabras más, palabras menos, que Mahoma sólo había traído violencia al mundo. Ante esto, muchos nos 
sentimos de nuevo en la época de Las Cruzadas. La razón secular no puede sino interpretar la religiosidad en el mundo actual como un lastre, y se lamenta de que una enorme porción de la humanidad sea presa, de uno y otro lado, de instituciones que desde hace ya mucho no viven en el presente. Dada la importancia que sin duda tiene el tema en la obra de Hegel, ¿qué claves ves en el filósofo para pensar la religión hoy? ¿Hay en Hegel, según tu juicio, elementos para renovar nuestros conceptos sobre la religión y la religiosidad en el mundo contemporáneo? ¿Hay en Hegel claves para un pensamiento postsecular (Habermas)?

J. I. Palencia: En tus últimas preguntas planteas ciertos tópicos que merecieran ampliarse: hay en Hegel, en toda su obra, asuntos vigentes. Mencionaba ya antes el de la identidad y la diferencia en relación con la tolerancia. Lo mismo puede decirse sobre subjetividad/objetividad; o praxis (aunque no use él el término) y objetivación; extrañamiento o enajenación, individualidad/ particularidad; totalidad concreta, todo esto en relación con la libertad y la historia. Particularmente, considero importante, aunque más especulativa y abstracta, la reflexión sobre la Idea, el espíritu y el absoluto como inmanentes y relativos al mundo, así como realizados-realizables históricamente y, por tal, relativos. Los términos o expresiones engañan a veces, o se prestan a interpretaciones exógenas. En el sistema de Hegel hasta donde yo lo comprendo hay elementos que permitirían entender que el espíritu, la Idea, el absoluto, son relativos, históricos, y no de otro mundo; pero nos marcan la pauta para trascender - transgredir- lo ya dado y, en este sentido, en su inmanencia, son trascendentes a "los pensamientos fijos y determinados".

Esto nos lleva a lo que llamas tú la razón secular, y citas a Habermas sobre las claves de un pensamiento post-secular. Para mí es totalmente claro que Hegel asume la secularización de la historia, de las instituciones, del mundo, dentro de la necesidad del proceso en la historia - por su formación reformada ni siquiera tuvo ocasión de ser anticlerical, aunque sí argumenta con fuerza por la laicidad del Estado frente a la institución eclesiástica. Ya en sus textos juveniles critica la positividad del judaísmo, a los fariseos de la época de Jesús, y la positivización del cristianismo (de Constantino a Carlomagno y la entronización del Sacro Imperio Romano Germánico). Lo importante de su obra es que él asegura que todo esto es contrario al espíritu del cristianismo.

Para él, utilizando expresiones teológicas, la encarnación del Verbo tiene un sentido redentor para la creación, para el hombre: la muerte de Jesús es la reconciliación, y la vida de la comunidad es la vida del espíritu en el mundo. La secularización -o desacralización- está para Hegel en germen en la vida y doctrina de Jesús que recoge el Evangelio: no se refiere al secularismo como ideología, sino a la expresión profunda de que el reino que Jesús predica está dentro de nosotros que habitamos el mundo -aunque el reino no es de este 
mundo, pues si lo circunscribimos o determinamos en las determinaciones de este mundo, lo finitizamos. Aquí cobran sentido expresiones de la Fenomenología, tales como el desgarramiento de buscar la afirmación del más allá en el más acá; el empobrecimiento de la fe cuando se le reduce a pensamiento, y la vida de la comunidad en el amor como representativa de la vida del espíritu.

El filósofo cristiano Maritain apunta o asevera en un texto de la mitad del siglo $\mathrm{xx}$, antes del concilio Vaticano II, que "la religión acaso sobrevivirá en las comunidades dispersas como en diáspora, en un mundo [...] que dejó de ser cristiano ya en su esencia..." Hegel no estaría de acuerdo con esta afirmación que implica a la religión con la reacción. Yo tampoco lo estaría: el cristianismo, por su esencia y como religión, es cosa de este mundo e implica la afirmación de la libertad de los hijos de Dios - la posibilidad de autodeterminación frente a lo otro como extraño o como otro. La religión, como el arte, son para Hegel expresiones o exteriorizaciones del desarrollo del espíritu que se autodetermina como idea realizada en la totalidad concreta. La religión y el arte, como la filosofía, son, así, históricos y, por lo tanto, superables en su configuración particular determinada. Pero Hegel no apunta a su exclusión sino a su comprensión.

[Hegel] puede considerarse arreligioso en su filosofía -aunque hable en ella mucho de la religión que bien conoce-, pero no es antirreligioso: para él lo importante es la organicidad, él dice unificación, de las configuraciones del espíritu tal y como es en y para sí, y busca en este movimiento del espíritu que se dirige a su propio mundo, a su propio presente, superar las diferencias entre forma y contenido, sujeto y objeto, propias del entendimiento; y saber de sí en su propio devenir: actuar, obrar, con racionalidad, en libertad.

Como escolio a lo ya dicho añadiría esto último:

La propuesta de Hegel puede parecer abstracta: el pensamiento, el espíritu, la historia, el derecho o el Estado; hay que entender su perspectiva, se trata de filosofía, esto es, saber, y este saber implica el desarrollo del concepto por la reflexión como totalidad: no el puro resultado, sino el proceso con su desarrollo.

La reflexión totalizante no es totalitaria, "todo depende de que lo verdadero no se aprehenda y se exprese como sustancia sino también y en la misma medida como sujeto", dice él en la Fenomenología (p. 15). El sujeto es pues conocido en su exteriorización; ahí donde se expone y se realiza. Su verdad está en la acción, no sólo en la contemplación de sí o del mundo en que se encuentra y, en esta acción, transformadora de la realidad, al transformar el mundo él mismo se transforma.

El pensamiento, el espíritu, la historia, el universo de la libertad que se realiza, no son para Hegel cosas de otro mundo o de otro autor: son el resultado, para el sujeto, de su acción objetivada y extrañada, si se quiere, como 
puesta frente a sí a partir del impulso de la vida natural, fundamental, como Begierde -apetencia dice Roces en su traducción-. Lo importante en el sujeto y en su formación es apropiarse de este impulso instintivo apropiatorio y mediarlo por la reflexión: mediarlo como impulso por medio del trabajo y reconocerlo como suyo en la obra realizada. La disciplina en el trabajo y la reflexión reapropiatoria de su efectividad (Wirklichkeit), constituyen para el sujeto, cultura (Bildung) y responsabilidad (Gewissen) de lo inmediato o de lo dado, superación (Aufhebung) de la inmediatez y de lo meramente dado como fáctico.

Así, Hegel nos habla de cosas muy actuales y concretas: el individuo -como singular, o como comunidad, como pueblo; o como espíritu (que no es sino la totalidad de las autoconciencias que se relacionan entre sí y se relacionan con su mundo-, su responsabilidad, su racionalidad, y su posibilidad -en el ejercicio de la libertad- de asumir, de asumirse, en una nueva responsabilidad y en una nueva racionalidad. Puede haber algo de optimismo en esto, pero es el horizonte de la libertad: "El punto de viraje a partir del cual se aparta de la apariencia coloreada del más acá sensible y de la noche vacía del más allá suprasensible, para marchar hacía el día espiritual del presente" (Fenomenología, p. 113).

E. Lazos: Muchas gracias, José Ignacio, por esta entrevista. 